\title{
SUBORDINACIÓN DE GÉNERO E INTERCULTURALIDAD MUJERES DESPLAZADAS EN CHIAPAS
}

\author{
Mercedes Olivera Bustamante
}

$\mathrm{E}$ n la actualidad encontramos en Chiapas una gran heterogeneidad cultural no sólo por la diversidad étnica de los grupos indígenas que conforman un poco más de la tercera parte de la población, sino también por las diferentes formas y niveles de su articulación al sistema capitalista y a los efectos de las políticas neoliberales del Estado, que han abierto un proceso de diferenciación social polarizante y un intercambio cultural tan intenso, que en poco tiempo han cambiado los límites entre lo indígena y lo mestizo, el perfil de las regiones y comunidades, así como la composición cultural y funciones de las ciudades ladinas que en los cincuenta todavía eran ejes rectores de la dinámica delas relaciones y cambios culturales en Chiapas (Aguirre, 1967). En la actualidad la expansión y dinámica neoliberal del mercado, la penetración de capitales transnacionales, la desestructuración de la economía campesina, el consumismo, el gran empobrecimiento de la población, la falta de fuentes de trabajo junto con la política clientelar, desarrollista y contrainsurgente de los gobiernos federal y chiapaneco marcan la dinámica cultural y son causa de las crecientes migraciones de la población hacia Estados Unidos y Canadá, así como de los desplazamientos de la población rural hacia las

Mercedes Olivera Bustamante, CESMECA- UNICACH Movimiento Independiente de Mujeres de Chiapas ciudades o a otras comunidades en donde encuentran protección a sus vidas y se construyen nuevos espacios, en los que, estableciendo nuevas dinámicas de interculturalidad económica, política, religiosa... resignifican su existencia y el entorno de sus nuevos asentamientos como sucede en San Cristóbal de Las Casas que, a despecho de los mestizos coletos que siempre se sintieron sus dueños exclusivos, se ha indianizado con los desplazamientos de indígenas (Morquecho, 2002).

Las migraciones y desplazamientos están en la base de casi todos los asentamientos de los pueblos históricos que formaron grandes civilizaciones, o de los que vivieron en pequeños grupos. En la situación actual, predominan los movimientos individuales o familiares sobre los masivos y, sus causas, siempre económicas y políticas, corresponden a estrategias de sobrevivencia en situaciones límite, cuya forma y destino varían de acuerdo con los momentos y contextos específicos que vivieron en sus lugares de origen y los obligaron a salir. En este trabajo nos referimos a desplazamientos de población colectivos y forzados en Chiapas, de los que podemos decir, con Joaquín Herrera (2002), que son producto de violaciones a los Derechos Humanos.

No podemos dar cuenta aquí de todas las formas de desplazamiento en Chiapas, que son muchas, dada 
su posición fronteriza y su marginalidad, así como la situación de guerra a raíz del levantamiento zapatista; nos limitamos a dos situaciones concretas de desplazamiento: los ocasionados por conflictos políticoreligiosos y el desplazamiento masivo de refugiados guatemaltecos al inicio de la década de los ochenta. Aunque hacemos mención a algunas causas y procesos históricos de estos desplazamientos, hemos puesto el énfasis en los efectos que han ocasionado en la vida e identidad de las mujeres, en las diferentes situaciones de interculturalidad en que han vivido en los lugares en donde se han asentado.

La investigación de campo sobre el tema se realizó a fines de 2002 y principios de $2003^{1}$; su objetivo original fue tener un diagnóstico que permitiera diseñar políticas para la atención a las desplazadas en Chiapas. Pero paralelamente a ese objetivo, nos propusimos propiciar a mediano plazo, su acercamiento al Movimiento Independiente de Mujeres de Chiapas a través del cual algunas de ellas han podido encontrar un espacio de organización y acompañamiento (Na'Snopel 2003)². El artículo se ha estructurado en tres partes, en la primera se hace una reflexión teórica sobre interculturalidad, género y desplazamientos; en la segunda, se exponen los diferentes procesos de interculturalidad mencionados y al final se hace una breve reflexión analítica, comparando las dos situaciones de interculturalidad.

\section{I \\ Posmodernismo, género e INTERCULTURALIDAD}

El desplazamiento ha dinamizado históricamente el intercambio cultural a tal grado, que desde hace muchos siglos no se puede hablar de culturas "puras". Pero el proceso de hibridación cultural, como le llama García Canclini (1989), es muy acelerado en la actualidad debido a la dinámica globalizadora del capitalismo, sobre todo por el dominio del mercado en la economía y por las políticas neoliberales facilitadas por la revolución electrónica y el desarrollo de los medios de comunicación masiva. Éstos liberaron el intercambio de la información y del conocimiento, han impulsado la expansión de la tecnología moderna y el consumismo de productos foráneos a todos los niveles de la población. En su dinámica dialéctica, los cambios estructurales han transformado también las estructuras estructurantes (Bourdieu,1997) de las identidades personales, sociales y colectivas: las cosmovisiones, la manera de ser, de pensar, de ver, simbolizar y valorar la realidad, que a su vez influyen en las transformaciones estructurales. El proceso de intercambio y transformación cultural entre dos o más grupos ha sido llamado por las corrientes posmodernas interculturalismo, que en el caso de la dinámica de los desplazamientos, se asocia a la vez a sus causas y consecuencias políticas y económicas; y constituye una característica de la inestabilidad social del contexto que los enmarca.

Pero el interculturalismo, que es un concepto posmoderno, no siempre se interpreta de la misma manera. La corriente de los posmodernos entusiastas al cuestionar los paradigmas positivistas y los dogmas del marxismo ortodoxo, proclaman el colapso total de la modernidad, de sus bases culturales y de sus paradigmas en ciencias sociales, en política, en arte y en filosofía. En cambio los posmodernos críticos como Habermas, consideran que la crisis de la modernidad, es parte de su propia dinámica, con lo cual "el posmodernismo no es sino la modernidad explicándose a sí misma, explicando sus propios conflictos irresueltos" (Hopenhayn,1995:58). En relación con la interculturalidad ambas corrientes enfatizan la interinfluencia y creatividad de los grupos en contacto, rechazando la interpretación mecanicista que enfatiza las imposiciones culturales de los grupos dominantes; sin embargo, las críticas a la visión unilateral del poder, ha llevado a posiciones relativistas extremas que al mistificar el dato empírico, otorgándole un poder omnicomprensivo, descontextualizan la cultura y sus 
dinámicas en relación con el entorno político e histórico en que se suceden. Al dar primacía a los signos sobre los sujetos relativizan el campo de la conciencia y de la razón, proclaman la prefiguración de un fondo humano y oculto, poblado de metáforas, sentimientos, afectos y encadenamientos incontrolables; exaltan el deseo polimorfo y critican el reduccionismo filogenético. Defienden la idea de que la sociedad consta de un tejido inextrincable de micropoderes y juegos de dominación locales más que universales cuya heterogeneidad y complejidad imposibilitan el conocimiento de las dinámicas sociales e invalidan las categorías de análisis que llaman metarrelatos (Osorio, 2001). A cambio, proclaman la exaltación de la diversidad y las diferencias, del individualismo estético y cultural, de la multiplicidad de lenguajes, formas de expresión y proyectos de vida y, consecuentemente, del relativismo axiológico.

Es verdad que tanto el liberalismo clásico, como el marxismo han invocado principios universales para acceder al conocimiento y, en el caso del materialismo histórico, han marcado pautas para entender el presente como parte de un proceso histórico de relaciones dialécticas y, ciertamente, cayeron con frecuencia en esquematismos y dogmatismos, pero no hay seguridad de que esto se deba sólo a las categorías y métodos de análisis o también al uso indebido que se ha hecho del conocimiento (Bastos y Camús, 2001). La vaguedad de la propuesta posmoderna encaja perfectamente en la idea de indeterminación respecto del futuro que para ellos marca el compás de los tiempos (Osorio, 2001).

Podemos admitir que la acción del posmodernismo ha sido un sano antídoto contra las tendencias etnocéntricas, racionalistas y mecanicistas de la sensibilidad moderna en las ciencias sociales. Sin embargo, con frecuencia el posmodernismo se ideologiza, disfraza sus juicios normativos con juicios descriptivos y remata contra sus propias premisas en nuevos reduccionismos que ponen en duda la validez de todo el quehacer de las ciencias sociales, incluyendo la teoría de género, encuadrándolas en la literatura y en la descripción etnográfica sin darles validez alguna como sistemas de representaciones que nos acercan a la realidad objetiva. Pero lo más preocupante de la ideologización de la retórica posmoderna es que "ha sido provechosamente capitalizada por el neoliberalismo para poner al día un ansiado proyecto de hegemonía cultural.., lo que muchos neoliberales ven, sobre todo desde los países industrializados, es la posibilidad de una reculturización que haga coincidir los gustos de la gente con la promoción de las políticas pro-mercado y con la consolidación de un sistema capitalista transnacional" (Hopenhayn, 1995: 165).

\section{Teoría de género y posmodernidad}

Reconocemos, desde una posición neomarxista, que el posmodernismo ha enriquecido a la etnología, a la teoría de género y al feminismo; pero al mismo tiempo advertimos en sus posiciones efectos retardatarios, contrarios al avance de las reivindicaciones feministas en la actualidad. Entre los aportes y coincidencias podemos mencionar la legitimación y reconocimiento de las diferencias. Precisamente partiendo de las diferencias sexuales sobre las que se han simbolizado las diferencias de género como construcciones históricas y sociales diversas, la teoría de género, sobre todo en la última década, ha hecho énfasis en las diferencias positivas y en la variabilidad de situaciones de género que viven hombres y mujeres dentro de los roles predeterminados por la sociedad, con privilegios marcados para los varones (Lamas,1996; Sendón y otras, 1994). A la par de reconocer las diferencias locales, personales y sociales, se reconocen la diversidad de estrategias y posiciones dentro del feminismo; así como también las diferencias entre mujeres y entre hombres. La atención que ponen los posmodernos en la diversidad de situaciones étnicas, campos socioculturales y momentos históricos, nos previene de los esencialismos y las generalizaciones 
infundadas a la vez que nos estimula a contemplar desde la reflexología la diversidad de las situaciones en todas sus dimensiones: en las relaciones, en las instituciones, en los modelos o imaginarios colectivos y en las subjetividades (Aparici, 1994).

El planteamiento posmoderno de enfatizar las diferencias y la diversidad como una riqueza personal y social, deviene en el reconocimiento de que las mujeres no queremos ser iguales a los hombres, queremos guardar nuestras diferencias sexuales y genéricas como elementos centrales de nuestra identidad. De esta concepción se han desarrollado varias corrientes que, en general se reconocen como feminismo de la diferencia. Sus posiciones, han enriquecido el desarrollo de la autoestima y fortalecido la identidad de las mujeres al ubicar la diferencia sexual y genérica como fuentes de valoración personal y social; pero también han surgido posiciones extremas que, al poner el énfasis en la aceptación y la sobrevaloración de las diferencias, descontextualizándolas de las relaciones de poder, consideran que las posiciones de las mujeres en la estructura social, en posiciones políticas excluyentes y en valores morales opuestos, son sólo sanas muestras de diversidad cultural, con lo que pobres y ricos, opresores y oprimidos, violadores y violadas por decir algo, podemos convivir y aceptarnos simplemente como diferentes obviando las desigualdades. El no contemplar las diferencias con sus significados dialécticos, sistémicos y estructurales, encamina a esas corrientes feministas a propiciar la naturalización y la justificación de la explotación, opresión y subordinación de las mujeres, auspiciando una tendencia conformista y desmovilizadora desde el punto de vista político. Algunas posiciones académicas de la diferencia incluyen planteamientos reduccionistas extremos como el no dar importancia teórica, ni estratégica a la existencia de un sistema global de relaciones desiguales (genéricas, sociales, políticas, económicas, etarias, generacionales etcétera) articulado desde lo personal y local hasta lo social-global, en cuya dinámica histórica están inmersas sine qua non, nuestras diferencias de género y toda nuestra existencia.

Un aporte del posmodernismo a la teoría de género y al feminismo es el rechazo a las verdades únicas y a las generalizaciones y, consecuentemente, el rechazo a las concepciones lineales del desarrollo. En este sentido la consideración de que el modelo de ser mujer es una construcción social históricamente determinada, nos obliga a tomar en cuenta que esos modelos son diferentes en cada sociedad y que también son diferentes de acuerdo con los tiempos y ritmos de desarrollo. Lo anterior implica que es necesario reconocer que no sólo hay una Historia Universal, sino también muchas historias dentro de las que hay conocer la especificidad de la posición de género de las mujeres en cada caso particular (Lagarde,1988). Consecuentemente, no podemos trazar una estrategia de cambio única, válida para todos los grupos étnicos, clases y sectores de la sociedad, como si todas las mujeres vivieran en idénticas situaciones y condiciones genéricas ${ }^{3}$ (Olivera, 2004).

Los conceptos de multietnicidad o pluriculturalidad nos llevan al reconocimiento de que nuestras sociedades mesoamericanas están conformadas por una gran diversidad de grupos sociales y que sus diferencias culturales y sus identidades étnicas deben ser reconocidas por el trabajo feminista; el concepto de interculturalidad nos es útil siempre que no olvidemos que ese proceso tiene entre sus causas expresiones excluyentes y diferenciadoras de poder como las conquistas, las expulsiones y los desplazamientos forzados; y entre sus consecuencias, posiciones desiguales y conflictivas de existencia.

También es importante señalar que el feminismo de la igualdad que reivindicamos, se plantea, con variantes, la utopía de construir una sociedad con relaciones de género sin discriminaciones, opresiones, explotaciones, ni subordinaciones; con la recuperación de nuestro cuerpo y la autodeterminación personal y grupal. Sin 
embargo, este objetivo queda fuera de las posiciones posmodernas, precisamente porque uno de sus planteamientos básicos es la negación de las utopías por considerarlas concreciones simbólicas de los metarrelatos modernistas. El rechazo posmoderno a las utopías, sobre todo a las que buscan la igualdad de género, clase y etnia o cualquier otro ideal emancipatorio, niega la posibilidad de la construcción de las identidades colectivas de las mujeres en torno a un objetivo político de liberación, y nos deja desarmadas para orientar la lucha por nuestras reivindicaciones. Señalamos que algunos problemas de la despolitización en que han caído algunas académicas y algunos grupos feministas tienen su origen en la aceptación acrítica de planteamientos posmodernistas. Debemos cuidar que el conocimiento minucioso de las especificidades étnicas y genéricas que recomiendan las corrientes posmodernas, nos lleve a reducir las relaciones sólo a las que empíricamente encontramos en nuestras investigaciones de campo olvidándonos de que las relaciones desiguales son parte estructural del sistema global de relaciones y le otorgan un carácter específico que algunas feministas han llamado patriarcal, por su funcionamiento sexista, excluyente, autoritario y vertical, donde históricamente las mayores cuotas de poder y los privilegios han sido para los hombres. El peligro de olvidarnos del carácter sistémico de las relaciones de género, etnia y clase nos puede llevar a pensar idealistamente que se puede alcanzar la democracia sin transformar las relaciones excluyentes de etnia, clase y género.

\section{Interculturalidad y desplazamientos}

En México y Centroamérica, la interculturalidad surge como un concepto relacionado a los sistemas y métodos de educación tratando de sustituir a los de multiculturalismo y multietnicidad usados por el indigenismo de las últimas décadas del siglo pasado que en su política de educación bilingüe y bicultural tomó en cuenta la diversidad étnica y lingüística, pero no la desigualdad social de los indígenas hacia el exterior y hacia el interior de sus comunidades (Schmelkes, 2001). Actualmente sin embargo, la interculturalidad no tiene un solo significado, unas veces se refiere simplemente a la educación bilingüe y bicultural, en otras se plantea una forma educativa integral con el objetivo de preparar a los indígenas para vivir en las dos culturas. Una tercera acepción hace referencia a una educación alternativa que incluya en igualdad en el proceso intercultural a todos los integrantes y culturas de una sociedad multiétnica (Bastos y Camus, 2001). Esta concepción supone la necesidad de establecer una relación horizontal entre los sujetos de la educación, al menos sin racismos ni discriminación social, como proponen los demócratas europeos para las políticas hacia los migrantes africanos (Juliano,1999).

El concepto de interculturalidad que adoptamos nos es útil para analizar desde el género los cambios sociales y culturales, - tanto en los aspectos trascendentes, como en los normativos ${ }^{4}$ - que las mujeres han tenido en sus vidas e identidades a través del proceso de desplazamiento y de reinserción en los lugares en donde ahora viven. Tanto el desplazamiento de población visto como efecto de las luchas entre poderes desiguales que obligan a salir a unos y posibilitan que otros se queden, como la reinserción, entendida como la gestión o lucha para obtener nuevos espacios para vivir y la forma de adaptarse a ellos, son procesos que aceleran la dinámica intercultural en tanto que al salir se rompe con lo viejo y se construyen formas nuevas de vida acordes a la cultura de los grupos que los reciben, a los que, a su vez les aportan elementos culturales nuevos. La disputa por el territorio y los espacios económicos, sociales y de control político, en el campo y en la ciudad, como dice María Eugenia Reyes (1998), conllevan tensiones y conflictos, implican contestaciones y retrocesos, que agudizan la dura competencia por la sobrevivencia y la tendencia cultural homogeneizadora del mercado. 
Desde el punto de vista de nuestro análisis es importante mencionar que, autores críticos a las posiciones que conciben la interculturalidad como un proceso de intercambio entre iguales, al analizar los cambios en el imaginario indígena causados por los migrantes que regresan de Estados Unidos, plantean la preocupación de que en el contexto de la globalización y las políticas neoliberales, la interculturalidad puede ser funcional al sistema al favorecer la imposición cultural que los países centrales imponen a los periféricos, a través del mercado con la consecuente devaluación de lo propio, de las culturas indígenas y nacionales (Herrera 2002, Bastos y Camus 2001).

Siguiendo este pensamiento, al analizar la indiferencia de los gobiernos estatal y federal ante los desplazamientos forzados en Chiapas, muchos de los cuales no son ajenos a su intervención, debemos preguntarnos si los procesos de interculturalidad promovidos desde el poder, incluyendo los desplazamientos, no son sino una forma más del sistema para eliminar los obstáculos que la diversidad cultural y étnica pueden representar a las necesidades del libre mercado de un sistema que nos ha colocado a las mujeres y especialmente a las indígenas, en una posición no sólo de extrema de pobreza, sino cada vez de mayor dependencia del mercado. Interculturalidad puede significar en este contexto el impulso a la construcción cultural enajenante en torno al consumo, a la despersonalización, al individualismo y a la competencia... Y, específicamente en relación con las mujeres, la aceptación de nuestra integración al mercado de trabajo en condiciones infrahumanas y aún más desventajosas que los hombres, resignificando nuestra subordinación al sistema patriarcal neoliberal, que ahora nos exige tener pocos hijos pero educados e instruidos eficientemente, para que trabajen como fuerza de trabajo barata en los servicios y empresas agroexportadoras de Estados Unidos y del norte de México o como asalariados sin derechos, ni prestaciones en las maquiladoras.
En la dinámica del conflicto intercultural entre poderes desiguales se generan múltiples contradicciones, que han ido transformando la conciencia social y la posición subordinada tradicional de los y las indígenas en resistencias y rebeldías, en contra de las subordinaciones y deshumanización del sistema, en contra de la injusticia y la guerra, en contra de los abusos y violaciones a los derechos humanos, en contra del sistema neoliberal. En este contexto de direcciones opuestas, concebimos la dinámica de la interculturalidad como expresión de intercambios desiguales y contradictorios entre poderes en oposición.

\section{II \\ INTERCULTURALIDAD EN DOS SITUACIONES DE DESPLAZAMIENTO}

No existen registros que nos permitan saber con cierta exactitud la cantidad de desplazados internos ${ }^{5}$ en Chiapas de 1980 a la actualidad, sólo sabemos con certeza que en los momentos de crisis económica y política, tan frecuentes en el estado, los desplazamientos internos se recrudecen. En la década de los ochenta las luchas campesinas y la represión gubernamental y de los ganaderos, produjeron importantes movimientos de población hacia la Selva Lacandona. Asimismo, en esta década se dieron las más numerosas expulsiones de indígenas católicos y protestantes (Hidalgo y Castro, 1999). En cambio, entre 1994 y 2000, se sucedieron los mayores desplazamientos por la guerra. Se calcula que la cantidad de personas que salieron al menos una vez de sus comunidades de 1980 a la fecha, puede llegar aproximadamente a cien mil; una vez pasados los momentos críticos, la mayoría regresó a sus comunidades (CIACH, 2000; CDHFBC, 2000 y 2001). Para 2002, según el informe del gobierno al Relator Especial para Desplazados Internos de la ONU, había 1261 familias desplazadas en Chiapas, es decir entre 9 mil y 10 mil personas, principalmente indígenas. 
Este número parece referirse sólo a los desplazados por la guerra ${ }^{6}$, los desplazados por conflictos político religiosos pueden ser hasta tres veces más y los guatemaltecos refugiados y sus hijos que se han quedado en Chiapas, oficialmente son algo más de 14 mil. En un cálculo grueso, se puede aceptar que los desplazados internos son alrededor de $50 \mathrm{mil}$, sin contar a los desplazados por motivos económicos. El informe menciona que a pesar de la política de reconciliación del gobierno actual sólo han regresado 265 familias a 16 municipios $^{7}$ porque las causas que originaron la salida no se han resuelto (Henríquez, 2002).

\section{A. Desplazados por los conflictos POLÍ́TICO RELIGIOSOS}

Los desplazamientos masivos de población indígena, sobre todo tsotsiles, por supuestos motivos religiosos, se iniciaron en 1974 en Chamula, se extendieron a los municipios como Chalchihuitán, Chenalhó, Mitontic, Tenejapa y otros, llegando a su clímax en la década siguiente y, aunque a partir de 1994 se han reducido, continúan dándose esporádicamente. La mayor parte de estos desplazados se han asentado en la periferia de San Cristóbal, principalmente al norte. La población hablante de lengua indígena ha aumentado significativamente a consecuencia de los desplazamientos; ya en 1995 los indígenas eran 35 000, más de la tercera parte del total de la población del municipio, que habitaban más de 93 colonias $^{8}$. Su presencia en la ciudad ha cambiado las formas de relacionarse con los coletos, que ahora ya no son ni ricos ni terratenientes en su mayoría (Hvostoff, 2001).

Los desplazamientos se han hecho por grupos familiares, que a veces han sido numerosos, de una misma comunidad; así la cantidad de mujeres desplazadas a San Cristóbal es un poco mayor a la de los hombres correspondiendo a la composición de la población. Las confrontaciones que originan las expulsiones se dan entre las autoridades políticas y religiosas tradicionalistas con los feligreses evangélicos y de diferentes sectas protestantes, pero también con los católicos que optaron por la teología india que impulsó el obispo Samuel Ruiz en la Diócesis de San Cristóbal. Los cambios religiosos fueron significativos; sacerdotes y religiosas de diferentes órdenes y nacionalidades, que tomaron la opción por los pobres junto con el ejército de jóvenes indígenas (varones en su mayoría) que formaron como catequistas, implantaron nuevas formas de catequesis, descentralizaron el culto de las cabeceras municipales llevándolo a los parajes, renovaron las prácticas religiosas dándoles un carácter liberador y sustituyeron a los miembros de las estructuras religiosas tradicionales o los integraron al nuevo funcionamiento; pero también incluyeron en el adoctrinamiento un programa de concientización social, desarrollo comunitario y recuperación étnica. El cambio se inició en la selva, se extendió por toda la diócesis; sin embargo, en las comunidades de los Altos en donde la costumbre religiosa estaba estrechamente ligada al funcionamiento político local tuvieron con frecuencia, fuertes dificultades para su implantación. En Chamula el descontento contra el obispo, el cura y los catequistas se convirtió en violento rechazo de los caciques tradicionalistas que al ver amenazado su poder decidieron la expulsión de los "samuelistas" y de los protestantes, incluyendo a un cacique converso, que sacaron por negarse a dar cooperaciones para las fiestas y a consumir trago. ${ }^{10}$

Hacemos notar que el adoctrinamiento renovador de estas corrientes, también fue un elemento que aceleró la interculturalidad en una correlación de fuerzas desigual entre la cultura tradicional y la modernidad cristiana generando violencia real y simbólica, que repercutió afirmando o cambiando "la costumbre" y la autoconcepción de los indígenas; en relación con las mujeres los cambios disminuyeron su exclusión, pues a partir de entonces, aunque en posiciones desiguales, cuentan con espacios propios de participación en las 
estructuras y ritos eclesiales. Desde el punto de vista de nuestro análisis es interesante anotar que en 1982, cuando se recrudecen las expulsiones, la iglesia católica y líderes protestantes promueven la constitución del "Comité de Defensa de los Amenazados, Perseguidos y Expulsados de Chamula" para hacer la denuncia pública del caciquismo y de los cientos de personas que habían salido de 70 parajes del municipio. Este Comité, de una manera excepcional, además de incorporar a las mujeres en su estructura y funcionamiento las incluye específicamente entre las reivindicaciones políticas que se plantearon: "Art.13. El Comité lucha por la libertad de las mujeres para que puedan estudiar, aprender y trabajar; Art.14. Luchamos para que a la mujer se le trate como persona y no como animal; Art 15. Luchamos para que los ladinos no abusen de las mujeres indígenas que trabajan en sus casas; Art.16. Luchamos para que no nos casen a la fuerza; Art.17. Luchamos para que no se digan cosas malas de las mujeres y no nos digan malas palabras porque somos indias" (Citado por Morquecho, 1992: 28).

A pesar de las dificultades, los evangélicos y los protestantes siguieron creciendo y reproduciéndose aun en Chamula y sus parajes; en medio de conflictos ${ }^{11} \mathrm{y}$ expulsiones periódicas no han dejado de luchar por sus derechos, tanto al interior de las comunidades como en las nuevas colonias a través de sus organizaciones surgidas en diferentes momentos, al calor de los enfrentamientos, como la Coordinadora Regional Indígena de los Altos de Chiapas (CRIACH), la Organización Indígena de los Altos de Chiapas (ORIACH), la Organización de Pueblos Evangélicos de los Altos de Chiapas (OPEACH), que luchan por su derecho a vivir en la tierra de sus antepasados, por la "paz en la religión" y respeto al Santo Patrón y a las buenas costumbres. Piden el cese de las persecuciones, encarcelamientos, multas, firma forzada de documentos, la imposición de cargos religiosos y garantías para sus vidas. Pero el gobierno hasta la fecha no ha cambiado su actitud de tutela, tolerancia y apoyo a los caciques que forman parte de varias generaciones priistas. (Morquecho, 1992).

Así, no obstante su expresión religiosa, los conflictos se enmarcaron siempre en las disputas políticas por el control del poder entre los caciques locales priistas confrontados entre sí a causa de las diferencias religiosas y de las políticas integracionistas y corporativizadoras del gobierno, implementadas por la Dirección de Asuntos Indígenas, y después por el INI, junto con diferentes agencias del partido oficial e instituciones del gobierno estatal. En esa posición el gobierno no sólo encubrió la ilegalidad de los desplazamientos, sino protegió y reprodujo la impunidad de los responsables. Hacia el interior las disputas caciquiles se relacionan con el control de los recursos económicos de la comunidad, tanto sobre las tierras cada vez más escasas e improductivas y la realización de los proyectos de desarrollo, como de los grandes aportes que todas las comunidades del municipio entregan para las festividades religiosas.

Sin detenernos más en el análisis de las causas de estos desplazamientos, apuntaremos algunos elementos que nos permitan entender el contexto conflictivo en que se dan los asentamientos en San Cristóbal y la forma en que se desarrolla hacia el interior la compleja vida de los asentamientos, que hacia el exterior se ven envueltos en un proceso de interculturalidad hostil neorracista de parte de los coletos, como se llaman a sí mismos los habitantes de San Cristóbal, y de manipulación discriminatoria desde el poder oficial que a través de diferentes instituciones y de su política clientelar, controla a los caciques y decide sobre la vida de los y las indígenas, articulándolos a las dinámicas neoliberales y haciéndolos cada vez más dependientes; y tratándolos como ciudadanos menores, sin reconocer su derecho a construir sus autonomías y a ejercer su autodeterminación.

La rebeldía en la Historia de Chamula se puede documentar desde la conquista, pero quizás las acciones 
históricas más significativas y violentas de los chamulas contra las estructuras de dominación se dan en el siglo XIX, cuando hicieron tambalear el poder local durante la mal llamada Guerra de Castas. (Rus, 1995a). Un elemento que aporta a las rebeldías chamulas es el carácter fuertemente corporativo y rígido de su organización social y de su gobierno tradicional; carácter que se ha reproducido al menos desde la formación del Estado mexicano hasta la actualidad, tanto en los diversos parajes del municipio como en las colonias de desplazados en San Cristóbal. Algunos autores vieron en esta corporatividad, articulada por los servicios religiosos y el consumo ritual, una forma de redistribución de la riqueza. Pero esa función, si acaso existió, no existe más, pues esas estructuras fueron resignificadas con el desarrollo desigual, la modernización capitalista y las diferentes formas de control político del Estado, originando una diferenciación social sui géneris en las comunidades y municipios indígenas, en tanto que, sin cambiar la posición marginal y el sentido corporativo de su funcionamiento, surgieron al calor de los proyectos desarrollistas fuertes diferencias económicas internas y grupos de poder caciquil, que han monopolizado o supeditado las estructuras de cargos religiosos y políticos, el ceremonial y el ritual comunitario a sus designios y privilegios económicos y políticos personales, concedidos y protegidos por el estado a cambio de la lealtad política incondicional al partido en el poder (Morquecho 1998).

En la ciudad, los desplazados han reproducido el corporativismo tanto en torno a los caciques priistas, como los líderes religiosos protestantes, nuevos caciques que no sólo han conservado su etnicidad resignificada en el contexto urbano, sino la han utilizado en sus relaciones con el gobierno, al que exigieron primero garantías para retornar y después negociaron clientelarmente los terrenos de sus asentamientos, servicios y espacios de trabajo en la ciudad.

Así los caciques, tradicionalistas, católicos o protestantes, funcionan como articuladores de la población indígena con las estructuras hegemónicas estatales, nacionales e internacionales. La ingerencia clientelar del gobierno se inicia en la región Altos durante la etapa Cardenista cuando el gobierno federal aseguró con las autoridades de Chamula y otros pueblos, miles de votos a cambio de los beneficios revolucionarios del "México Nuevo": formación del sindicato de trabajadores de las fincas, promesa de dotaciones ejidales, ${ }^{12}$ servicios y desarrollo urbano de las cabeceras municipales, que de ser centros ceremoniales se convirtieron en centros políticos y comerciales desde donde se reprodujo la dominación clientelar hacia las comunidades y se facilitó la intervención gubernamental y partidaria ( $\mathrm{PRM}^{13}$ y Dirección de Asuntos Indígenas de Chiapas) para imponer, sin tomar en cuenta el sistema de cargos, a maestros y promotores en las presidencias y otros cargos municipales que formaron la nueva casta de caciques usureros que, además de tener el control municipal, se apropiaron del comercio de granos y alimentos, de los transportes y servicios y hasta la fecha monopolizan el control político y religioso en la región (Rus, 1995 b; Morquecho 1998).

Las pugnas entre caciques; entre caciques y la clase política, y, entre caciques y diferentes sectores de la población han constituido un panorama permanente con dinámicas muy complejas, en donde las arbitrariedades del poder local, estatal y nacional, se ocultan tras la máscara de la defensa de las costumbres, la religión y la cultura, como sucede con las expulsiones de quienes critican e impugnan el poder caciquil. Pero esta forma corporativizada de control, ejercida por caciques, se reproduce entre la población desplazada, cada colonia y cada iglesia tiene sus líderes identificados. ${ }^{14}$ La mayor parte de las familias desplazadas pertenecen a organizaciones políticas y religiosas que en conflicto y fraccionamiento permanente son controladas por líderes que funcionan como caciques pagados por el gobierno, por diferentes partidos y por los mismos desplazados a fin de obtener protección. ${ }^{15}$ Las organizaciones de 
desplazados se han multiplicado, no sólo por la expansión y diversificación de los sectores, sino también por un flujo creciente de recursos económicos e intereses políticos que han creado conflictos entre los líderes y facciones desembocando en un sistema de relaciones muy complejo, competitivo, en donde con frecuencia anidan la violencia social, la delincuencia y la corrupción. Cada colonia tiene un representante que pertenece a una de las cinco o seis organizaciones de representación política concesionarias en su mayor parte del gobierno municipal de San Cristóbal. Algunas agrupan a los miembros de una o varias sectas protestantes e "independientes" como la OPEACH, otras son territoriales. La diversidad se da también en el ámbito económico: en 1997 había en la ciudad 15 asociaciones de microbuses, 12 de "combis" y 21 de taxis la mayoría predominantemente de indígenas desplazados (Isunza, 1997, Hvostoff 2001), otras controlan la madera, el carbón como, Vachaj'meh; también son más de siete las organizaciones que tienen concesiones para el abasto de mayoreo en ciudad y que han abierto nuevos mercados públicos desplazando a los ladinos de este sector ${ }^{16}$; las alianzas entre esas organizaciones son inestables, pero de ellos dependen miles de familias desplazadas con diferentes niveles de ingresos, pero que se siguen identificando como indígenas urbanos; en la actualidad el ser indígena no implica necesariamente ser pobre.

Desde fines de los noventa los desplazamientos "religiosos" aminoraron, aunque se siguen dado esporádicamente y la OPEACH no ha cejado en sus reivindicaciones. La distensión desde lo religioso cobró formas simbólicas de reconciliación en la construcción de un templo evangélico, a unos cuantos kilómetros del centro ceremonial de Chamula y en la peregrinación de desplazados católicos y protestantes de San Cristóbal a Chamula, el día de San Juan. En 1994 las expulsiones se redujeron a consecuencia del conflicto armado; algunos católicos desplazados, como los de Chalchihuitán, retornaron a sus comunidades. También regresaron cientos de evangelistas expulsados de varias aldeas de Chamula, bajo la protección del grupo armado "Guardián de mi Hermano"; pero durante los 15 meses que se mantuvieron en resistencia hubo varios enfrentamientos con los tradicionalistas que culminaron, en 1995, con un choque sangriento en la Comunidad de Arvenza y la intervención del gobierno federal y nuevos desplazamientos.

A la relativa distensión se han ido abonando otras causas, entre ellas que el PRI perdió las elecciones presidenciales de 2000 y que el gobernador actual es protestante, además de que oficialmente dejó de ser priista. Por otra parte, en Chamula se dio una ruptura al interior del grupo de caciques, que provocó la destitución del presidente en 1995, con lo que cambió la correlación de fuerzas entre los diferentes grupos. Ahora “....del linaje de los Collazo, unos detentan el gobierno municipal en Chamula y otros son dirigentes de la OPEACH, que cuenta con una amplia base social tanto en Chamula como entre los desplazados en San Cristóbal". También cuenta que las políticas neoliberales han promovido un nuevo tipo de relaciones entre la elite coleta y los caciques de Chamula; por ejemplo, "a través del proyecto turístico Ruta Maya, los caciques chamulas acaparadores y transportistas, se vieron obligados a pactar con los expulsados para evitar posibles agresiones en San Cristóbal" (Morquecho, 1998: 36-37).

Desde San Cristóbal varias organizaciones de desplazados apoyaron el levantamiento zapatista y exigieron al gobierno la regularización de sus terrenos. El gobierno aprovechó el apoyo internacional "destinado a la construcción de la paz" para solucionar el problema; pagó a los dueños coletos de los predios que ocupaban los desplazados en la Hormiga y otros lugares de la periferia al norte de la ciudad, cantidades exorbitantes (Hernández L, 1994). Con la regularización los desplazados pasaron de invasores a propietarios urbanos con mayores compromisos clientelares con el gobierno los que ocasionaron nuevas divisiones e inconformidades 
internas y cambios en el objetivo de las movilizaciones. Pero además, simbólicamente, al aceptar los coletos que los indígenas vivieran en "su ciudad" a cambio del dinero que recibieron, se dio un golpe su racismo excluyente y se aceptó formalmente la articulación del poder indígena en la dinámica de la ciudad. Ahora la discriminación racista se expresa más a través de las políticas gubernamentales asistencialistas en las que los líderes indígenas son intermediarios que en las relaciones personales, exceptuando, como veremos después, a las indígenas que trabajan en el servicio doméstico y la limpieza en los restaurantes, hoteles y centros nocturnos.

A pesar de las contradicciones del complejo mundo de relaciones en el que participan, los caciques indígenas de la ciudad también han acumulado un importante poder y capacidad negociadora al tener bajo su control a la población desplazada, al territorio de sus colonias, a la mayor parte de los mercados públicos y a buena parte del transporte urbano; constituyen una fuerza política que no se puede desconocer y que con frecuencia se sale del control del gobierno y rebasa la fuerza de los ladinos. Por ejemplo, en las elecciones de 2000 "los indios" determinaron la elección del presidente municipal actual de San Cristóbal. Después de más de dos décadas de luchas, los expulsados han dejado de ser una fuerza subordinada, han emergido como una nueva fuerza económica, política y social, con la cual el estado y el municipio tienen que negociar. ${ }^{17}$

\section{Repercusiones en la situación y condición de género de las mujeres}

A este reacomodo de fuerzas, hay que agregar que los desplazados de San Cristóbal han creado un nuevo sistema de relaciones y de cultura que ya no es la de sus comunidades, ni tampoco es la de los coletos de San Cristóbal, sino una propia que ha resignificado lo indígena en el proceso creativo de su adaptación y cambio. El rompimiento con las estructuras religiosas tradicionales de sus comunidades de origen, se refleja en el surgimiento de nuevas identidades en los desplazados que se podrían llamar de ciudadanía étnico-urbana que de alguna forma se ha extendido a muchas mujeres que no sólo tienen la credencial de votar porque se las exigen para participar en los programas gubernamentales, sino también porque son integrantes de base en sus organizaciones y cooperativas de artesanas por ejemplo, que no escapan a los procesos de diferenciación económica.

"Desde que nos apoya el gobierno nuestras artesanías se venden mejor.., antes, cuando llegamos sólo hacíamos cinturones que vendíamos por la calle... ahora bordo camisas y soy presidenta de la cooperativa, compramos los bordados de otras mujeres, a veces viajo a Tuxtla o hasta la capital... pero vemos que estén bien los bordados y tengan buena presentación porque si no los regresan porque no sirven para el extranjero... aquí por cada camisa pagamos cien o ciento cincuenta, según el tamaño, les damos la tela y los hilos...en otras partes les pagan menos... cada camisa lleva 2 semanas para acabarla... en las tiendas se venden a los turistas por más de seiscientos... a las mujeres de mi colonia les gusta traer sus bordados aquí conmigo porque es seguro, se vende al gobierno pero la paga a veces tarda y las mujeres no entienden. A mi me conviene porque tengo paga aparte, ...no nos pagan lo justo, pero las mujeres necesitan el dinero y si venden aquí no tienen que ir vendiendo por la calle..." 18

La distensión también se refleja en la flexibilidad en las relaciones sociales, las mujeres ya no tienen que casarse obligatoriamente con alguien de su misma etnia o comunidad y sus roles ya no están sometidos a la rigidez de la costumbre, aunque la moral cristiana sigue funcionando como una limitante a su autodeterminación. La nueva situación de flexibilidad religiosa en las colonias ha dado la posibilidad de que se forme un núcleo indígena musulmán en torno a uno de los dirigentes más connotados; núcleo que en 
todo caso, es un nuevo actor del complejo panorama cultural de San Cristóbal.

A nivel de las subjetividades, el impacto del desplazamiento se fue procesando aunque las mujeres aún recuerdan vivamente los miedos, indignación y gran desconcierto que tuvieron al llegar a vivir en la ciudad. El dejar sus casas, sus tierras, sus muertos, sus montes dentro de la cosmovisión maya significa romper con los lazos trascendentes de las relaciones con la naturaleza y los dioses, significa entrar a lo desconocido, "sin la protección de los antiguos" es "como una mata sin raíces" dijo una mujer en uno de los talleres que hicimos como parte de la investigación. Efectivamente fue quedarse sin otra posibilidad para sobrevivir que asumirse plenamente como parte activa de sus iglesias liberadas, de sus estructuras políticas y de la disputa del poder entre ellas; en este sentido el sentirse en "territorio libre" no sólo ha sido una de las causas de la proliferación de las sectas y de la gran cantidad de templos en las colonias de desplazados, sino también de los fuertes cambios que se dieron, sin dejar su posición subordinada a la autoridad masculina, en las identidades de las mujeres.

A nivel familiar los rompimientos significaron con frecuencia la desestructuración de redes de solidaridad con los parientes del mismo linaje o familia extensa. A nivel material no tener un lugar en donde vivir, sembrar y mantener a sus borregos, no sólo las colocó en una situación vulnerable sino les cambió la forma de su sobrevivencia campesina por lo urbano y hostil, en donde buena parte de sus sabidurías de siglos les dejaron de ser útiles, por eso "tuvimos que ponernos las pilas, aprendimos a movernos en la ciudad, a buscar trabajo, a organizarnos como mujeres y a movilizarnos para que el gobierno resolviera", dijo Hortensia representante de Santo Domingo.

El desplazamiento implicó que las mujeres buscaran cómo "mantener" cotidianamente a su familia. No tener maíz, ni un solar en donde sembrar verduras, las colocó en la situación de que "hay que comprar todo" y eso les obligó a integrarse al mercado de trabajo generalmente en situaciones de gran vulnerabilidad, sin embargo, en general, fue más fácil para ellas que para los hombres encontrar trabajo. Al principio muchas se dedicaron a hacer, vender y repartir tortillas, trabajo que dejaron cuando subió de precio el maíz y se multiplicaron las "tortillerías de maseca" en la ciudad; muchas, sobre todo las jóvenes que a su llegada ya dominaban el español, se acomodaron en el servicio doméstico, de tiempo completo en la producción artesanal o en la venta de frutas y verduras en pequeños puestos improvisados en la calle, oponiendo su presencia al racismo de los coletos y defendiéndose de las injusticias de los dirigentes.

'No tenía nada pue', ni siquiera era tuyo el cuarto pa dormir..., las señoras salimos a la calle a vender faja, pulsera, cualquier cosa... después, con mis hijitos conseguimos un lugar para vender... lo que me jodía siempre era el modo de las cashlanas, todo lo querían regalado y si les decías te tratan de india alzada... a cada rato tenías que salir de un lado a otro, los priistas del mercado no querían que vendiéramos... caso es de ellos la calle pue'?"

"Las mujeres que tenemos puesto en el piso del mercado chiquito, muchas no tenemos marido... solitas mantenemos los hijos, la casa es arrimada y sólo vamos sacando cada día para la tortilla y comer lo que hay... No me gusta que tengo que pagar todos los días para que me dejen vender... los encargados quieren que venda lo que van repartiendo, si manzanas, si tomates, si otras frutas... Lo dan y en la tarde te pasan recogiendo el precio de lo que te dieron, que ellos ponen... para mi queda muy poco, diez o doce pesos cuando se vende bien... ellos sí ganan más porque tienen muchas que venden y todas les pasan recogiendo... Los hombres de la organización son indios iguales, pero son ricos... ellos mandan, saben lo que hay que hacer...” 
Pasados los años, nos dijeron las desplazadas "nos acostumbramos a vivir en la ciudad", "ya no queremos regresar a donde nos pueden matar y no nos dejan vivir". A pesar de que muchas no tienen asegurada la posesión de los lugares donde viven, dicen que les gusta más vivir en la ciudad, se sienten más tranquilas, "está cerca el mercado, hay transportes, hay escuelas y clínicas y, aunque sea por poco, podemos trabajar" El asentamiento en la ciudad, que para algunas lleva más de 30 años, conjuntamente al hecho de hijos nacidos y casados en San Cristóbal ha dado nuevo sentido a su existencia, para muchas las angustias del desplazamiento han quedado atrás. Las nuevas desplazadas, además de que son pocas, al llegar se encuentran con parientes, conocidos y correligionarios, que a pesar de lo difícil que es, les han hecho menos dura la reinserción. De cualquier manera los desplazados son muchos para las áreas que ocupan y se han convertido en elemento de presión para el suelo y los servicios urbanos que cada vez resultan más insuficientes, la competencia por el trabajo y los recursos va socavando las solidaridades, agudiza los problemas sociales y la delincuencia y la violencia sexual.

Las relaciones entre parejas y entre padres e hijos también se han transformado, las mujeres en general reconocen que tienen más libertad que cuando estaban en la comunidad, ya no tienen que pedir permiso para salir y el disponer de su dinero les da seguridad y reconocimiento de los hombres, aunque sigue habiendo quienes les "sacan el dinero para embolarse" a pesar de que su religión se los prohíbe. La mayor parte sigue reconociendo a los hombres como jefes de la casa, aun cuando están ausentes, dicen que sí tienen que obedecerlos pero muchas opinan que sólo obedecen cuando está bien lo que piden y ellas están de acuerdo; lo cierto es que las mujeres trabajan fuera de la casa y siguen teniendo como obligación el trabajo doméstico en el que reproducen su actitud de servicio permanente para toda la familia. Se puede decir que las mujeres desplazadas han aumentado mucho su trabajo en relación con su vida anterior, pero ya lo asumen como parte de su vida actual, es decir han resignificado su condición subordinada, la nueva cultura ha naturalizado nuevas formas de desigualdad e injusticia hacia ellas. A la doble o triple jornada hay que aumentar los problemas con los hijos, con la delincuencia, el alcoholismo y la drogadicción que los amenazan y con la pérdida de la identidad étnica. Muchos niños y jóvenes ya no hablan el idioma de sus padres y no tienen interiorizados ni los valores étnicos, ni la vida en comunidad, rechazan lo indígena, "quieren vivir en el centro, tener una carrera y ser como "cualquier coleto." 19

\footnotetext{
"Tenemos miedo de llegar noche a la colonia, hay muchos bolos y drogadictos, han robado a muchos y hasta han violado a varias muchachas... el problema más grave son las drogas, ya la venden a los niños en las escuelas... muchos jóvenes ya se han perdido por las drogas... no sabemos qué hacer, no hay trabajo ni estudio para ellos, mi hijo de 16 años ay nomás está, se junta con sus amigos y muchas noches no regresa, su papá lo golpea pero no entiende, llega mal y nos amenaza... nos dice indios pendejos...”
}

Otro problema que señalan las mujeres es el abandono de sus parejas, muchos han ido a buscar trabajo fuera y no regresan, pero como las casas y el terreno son de ellos, son víctimas de despojos con alguna frecuencia, pero lo interesante es que, por lo menos algunas defienden sus derechos:

"El Lorenzo me dejó con mi criatura, mejor que se fue porque regaña mucho, toma y pega todos los días... Dicen que está en México, su familia quiere que salga yo del cuarto que con trabajos hicimos, dicen que no es mía, la quiere uno de sus hermanos que se va a casar y dice que él ya se lo dio a cambio de una deuda... Yo no voy a salir... ya lo acusé de abandono, pido la casa para mi hija... Tengo miedo de que por fuerza me saquen, la organización no mira por mí, apoya a ellos..." 
La reinserción en la ciudad modificó significativamente la situación de las mujeres y resignificó su posición de género, clase y etnia al adaptarse al nuevo contexto intercultural urbano. Aunque ahora tienen nuevos espacios de participación y muchas tienen posibilidad de moverse más libremente en ellos y cuentan con ingresos propios, siguen siendo subordinadas a las decisiones masculinas, a las patronas que las explotan y las discriminan, al mercado que no les paga lo justo por su trabajo, a las organizaciones y líderes corruptos, a la manipulación del gobierno y los partidos, a las imposiciones poblacionistas del BM que ahora controlan la fecundidad de las mujeres a través del uso de anticonceptivos y operándolas sin que ellas siquiera se enteren (Olivera, 2000).

No obstante, los cambios son significativos, sus identidades en general las alejan de la pasividad y el conformismo, la dureza de sus vidas las ha hecho descubrir sus fortalezas internas, desarrollar sus capacidades, tener una participación pública y reclamar sus derechos. Las mujeres se han integrado a la dinámica económica y política de sus comunidades, hay algunas lideresas entre los comerciantes de Merposur, varias de las colonias están representadas por mujeres:

“... participamos en las asambleas, ya no nos hacen un lado fácilmente, porque ahora sabemos que tenemos derecho a participar y decidir. Es más, como los hombres se han ido al norte o están trabajando todo el día, ahora hay más mujeres que hombres en las asambleas de las colonias y somos mujeres a las que nos tocan los cargos y las comisiones. Yo soy representante de mi colonia por este año, a veces los hombres me quieren mandar pero no me dejo"

"Las familias que vivimos aquí en el eje dos, tenemos más de 8 años que tomamos la tierra, pero no se ha regularizado porque el dueño que aparece murió y ahora ya no se sabe quien es el dueño, dicen que el Banco porque el difunto tenía un préstamo que no pagó, pero el Banco no presenta los papeles, así se ha ido alargando y aunque no nos vamos a salir, el problema sigue... mensualmente tenemos que dar cada y quien cien o ciento cincuenta pesos para los gastos de los dirigentes, si se hace la cuenta por más de ciento cincuenta familias que somos pues ya es algo lo que van sacando y no vemos claro lo que hacen... Las mujeres protestamos en la asamblea y nos dijeron que lo hagamos nosotras la gestión... dijimos que sí y ahora pedimos la ayuda de un abogado, porque ya tenemos derecho a que se nos reconozca por los años que llevamos viviendo..."

Las mujeres, sin participar en las negociaciones que hacen los líderes de sus organizaciones, que hasta ahora sólo son hombres, participan en los proyectos que han introducido las ONG o son parte de los programas del gobierno:

"Ahora ya no vengo a los talleres porque no hay tiempo... me dieron cargo en Oportunidades..., me toca estar en las reuniones en San Cristóbal y traer los avisos a las madres... lo que me cuesta más trabajo es andar viendo en las casas que las mujeres alimenten a sus hijos con el dinero que reciben y no lo gasten en cualquier tontería o que los papás compren trago con el dinero... ellas dicen que no alcanza para nada... que es una limosna, que las obligamos a ir a la clínica y tomar anticonceptivos... no les gusta, se les olvida tomar las pastillas, por eso es mejor que se inyecten, pero tampoco quieren, dicen que es en contra de la voluntad de dios... otras sí cumplen... a mi este trabajo me trae enojos con ellas, pero lo poco que saco me ayuda en mi gasto, pues aunque mi marido es taxista no me alcanza lo que me da..."

En la nueva cultura indígena urbana, a pesar de la gran heterogeneidad que presenta la situación de las mujeres, podemos decir que en general se ha transformado significativamente, sobre todo en lo que respecta a los espacios de participación política, al nuevo 
sistema de relaciones y a su rol en la familia al convertirse muchas veces en las principales abastecedoras del hogar; con ello su posición de género, en las nuevas comunidades, ha mejorado expresándose en una mayor capacidad de negociación y en la defensa pública y privada de sus derechos como mujeres, así como en el acceso a puestos de representación y de dirección a determinado nivel. Sin embargo, su condición de género así resignificada presenta nuevas y viejas desigualdades y subordinaciones importantes, por ejemplo, el sobreesfuerzo que significa trabajar jornadas largas para mantener cotidianamente a la familia, sin dejar de ser responsables del trabajo doméstico; la pobreza y la dependencia mayor del mercado; el sometimiento ineludible a los líderes para resolver la sobrevivencia; en los nuevos problemas que acarrean las relaciones intergeneracionales, en el aumento del número de madres solteras y en la sobre explotación y violencia social y sexual a que están sujetas. Desde el punto de vista étnico, aunque hay una pérdida en la cultura material en muchas colonias, su identidad tzotzil se conserva sobre todo en las generaciones adultas, urbanizándose y ciudadanizándose al adaptarse a la vida de San Cristóbal. En las generaciones de jóvenes y de niños nacidos en San Cristóbal se nota una tendencia mayor al modo de vida ladino y a la pérdida de la lengua. No obstante, ante los retos que han tenido que resolver en la ciudad su identidad de mujeres fuertes, activas y participativas, ya presente en ellas desde sus comunidades de origen ${ }^{20}$, se ha reafirmado.

\section{B. Refugiadas guatemaltecas “ASIMILADAS" A MÉXICO}

El caso de las refugiadas guatemaltecas que decidieron integrase a México es un caso que ejemplifica otras formas de interculturalidad en contextos que podemos llamar primero de emergencia y después de tolerancia forzada en donde la caridad cristiana y el asistencialismo se mezclan con el rechazo racista y xenofóbico y la explotación.
A principios de la década de los ochenta se da el gran desplazamiento de más de seis mil familias guatemaltecas que, aterrorizadas, se refugiaron en Chiapas para salvar sus vidas. Llegaron huyendo de la estrategia contrainsurgente de "tierra arrasada" aplicada por el ejército guatemalteco en contra de la población civil que, en forma organizada apoyaba la insurrección armada de las organizaciones político militares que después formaron la Unión Revolucionaria Nacional Guatemalteca (URNG). La guerra de Guatemala lanzada por los gobiernos militares, no tuvo fin sino hasta la firma de los Acuerdos Paz en 1997 y tuvo costos muy altos para los guatemaltecos. ${ }^{21}$

A su llegada, el gobierno mexicano, que no había firmado el Estatuto de Refugiados de la ONU, se resistió a reconocerlos. Por eso, durante los primeros días el Ejército Mexicano los regresó con violencia a su país colocándolos entre dos fuegos, aumentando su angustia y terror. La intervención de la Diócesis de San Cristóbal ante la Secretaría de Gobernación logró que las autoridades fronterizas y el ejército los dejaran entrar; $\mathrm{y}$, con su apoyo, los guatemaltecos fueron recibidos solidariamente por la población católica de la región. Posteriormente la Comisión Mexicana de Apoyo a los Refugiados, diversas ongs y el Comité Cristiano para Refugiados se encargaron de su atención con financiamiento de ACNUR (Olivera 1994 y 1999).

En un primer momento los desplazados se asentaron en la zona fronteriza, primero en lugares muy cercanos a la zona limítrofe, esperando regresar en poco tiempo a sus comunidades, después, ante la persecución del ejército guatemalteco en contra de ellos ${ }^{22}$, aun estando en territorio mexicano, se adentraron para asentarse en los municipios de Margaritas, La Trinitaria, La Independencia, Ocosingo, Comalapa y Bella Vista e incluso más de 17 mil, casi la mitad de ellos, fueron trasladados poco después por el gobierno mexicano a campamentos en los estados de Campeche y Quintana Roo. 
No es posible en este artículo describir todos los acontecimientos que se sucedieron durante los 12 años o más que pasaron los refugiados en México. De acuerdo con lo que nos interesa nos limitaremos a mencionar, con cierto orden cronológico algunos acontecimientos que las mujeres guatemaltecas en proceso de reinserción en México recuerdan vivamente de sus relaciones con el gobierno y la población mexicana y que nos ilustran sobre el proceso de interculturalidad que yo llamo de control opresivo, xenófobico y racista.

Por sentirse seguros al salvar sus vidas y recibir la hospitalidad de los cristianos chiapanecos, toman una actitud de agradecimiento y subordinación que los acompañó durante todo el refugio, que no lo viven como un derecho internacional sino como un favor. Esa actitud se construyó en medio de ambivalencias, las mujeres recuerdan cómo

"...los mexicanos con los que llegamos nos obligaron desde que entramos a quitarnos nuestros trajes, porque tenían miedo que los ejércitos o la migración nos encontraran y eso les causara un perjuicio...las que no hablábamos castellano, querían que todo el tiempo estuviéramos silencias"

Estas y otras normatividades que después les impuso la COMAR (Na'Snopel, 2003) como prohibirles salir de sus campamentos sin autorización y sólo poderse mover en la zona fronteriza, ayudaron a que el terror ya violentamente interiorizado con las masacres, muertos, desaparecidos y persecuciones que vivieron en Guatemala, permaneciera grabado en sus identidades mucho más tiempo y que la inseguridad volviera a ser la tónica permanente de sus vidas. Juanita, una de las dirigentes me decía al respecto:

"en México venimos a saber qué es ser guatemaltecas, muy distinto que ser mexicanas; muchas mujeres que sólo hablan su idioma, no se sentían guatemaltecas allá, aquí lo vinieron a saber".
La atención médica fue importante, muchos niños llegaron deshidratados y con infecciones, el hambre y la desnutrición eran problemas generalizados, mujeres embarazadas o que abortaron en el camino fueron atendidas en el hospital de Comitán, la mayor parte necesitaba terapia de apoyo para salir de su estado de angustia. Eso lo recuerdan las mujeres entrevistadas con mucho agradecimiento pero también con mucha añoranza, porque desde que se fue el ACNUR de Chiapas "ya no tenemos a dónde ir, ya no tenemos derecho a doctor ni a medicina"

La forma asistencialista en que muchas veces se les canalizó el apoyo de ACNUR o de la solidaridad cristiana, reforzó en algunas sobre todo las que vivieron en las zonas áridas e inhóspitas de Comalapa los sentimientos de minusvalía y subordinación pero sobre todo de impotencia.

"Nos acostumbramos a recibir los alimentos, no teníamos que hacer nada para recibirlos, pero a veces nos daban latas que no nos comíamos y aceite que nos hacía daño, pero ni modo pues eso era lo que había, no podíamos hacer otra cosa"

El reconocimiento de visitantes que les dio Migración (FM8), no les permitía trabajar legalmente y aunque después se las cambió por la de residentes temporales con derecho a trabajar (FM3), las posibilidades de hacerlo siempre fueron limitadas y mal pagadas. El trabajo al que accedieron fue el peonaje temporal o acasillado, siempre con fuertes márgenes de explotación. En la zona de Margaritas, los y las refugiadas vivieron en los ranchos y ejidos trabajando en los cafetales de los dueños, quienes los sometieron a una relación servil de gran injusticia que nunca detuvo la COMAR.

"Toda mi familia trabajábamos para el dueño, teníamos que cortar, lavar y secar el café sólo por 8 pesos al día ${ }^{23}$ los hombres y 4 pesos las mujeres, si 
teníamos pollos no los podíamos vender fuera, él nos los compraba por 6 pesos, lo huevos los quería siempre regalados... del maíz que le sembrábamos sólo nos daba un puchito cuando era la cosecha, decía que ACNUR nos mantenía y nosotros no le pagábamos nada por vivir en su tierra... lo peor era que siempre nos debía la paga, decía que no tenía dinero hasta que vendiera el café, en cambio a los peones mexicanos si les pagaba"

Exceptuando a los que se asentaron en terrenos adquiridos a través de la iglesia o el gobierno, los refugiados siempre estuvieron en una situación de gran inseguridad e inestabilidad económica que se reflejó en su movilidad buscando en donde vivir y trabajar, y en el aumento significativo de campamentos: de 64 para 1986, a 124 en 1992 (Olivera, 1994: 11).

La situación en que vivieron las mujeres refugiadas en Chiapas dentro de las grandes deficiencias y carencias, fue muy heterogénea en la seguridad de tener en donde vivir y trabajar, en la cantidad de terreno que tenían para vivir, en el acceso a los servicios, etcétera. Pero había algunos elementos culturales que todas compartían en mayor o en menor grado: el control opresivo de Gobernación a través de la COMAR, un fuerte sentido de la colectividad y organización y el deseo de retornar a su país.

Dos elementos hicieron reforzar en la frontera el control y vigilancia de Gobernación y del Ejército a partir de los ochenta, dentro de su programa de "Seguridad Nacional". Por un lado la "amenaza guerrillera de Guatemala" y por el otro, la presencia de grupos revolucionarios en la selva. De alguna manera se consideraba a los refugiados parte del movimiento revolucionario de su país y aunque las relaciones con las organizaciones guatemaltecas no eran directas, la mayor parte de las familias refugiadas en algún momento antes de su salida pertenecieron a organizaciones de masa que fueron bases de la guerrilla. COMAR tenía esto muy presente y a través de todos los programas y proyectos de asistencia, ejerció siempre un fuerte control opresivo sobre ellos:

"La comar siempre nos tuvo apartados de los mexicanos, sólo para el trabajo los veíamos, saber por qué no les daba permiso de llegar a vender, pocas veces íbamos a las celebraciones, cada campamento levantó su iglesia... En los campamentos tenía muchos "asistentes de campo" que más bien eran como policías que querían saber todo lo que hacíamos, llegaban a cualquier hora y sin pedir permiso se metían en las casas...; siempre estaban en las reuniones y presionaban al ACNUR para que ya no trabajara con las ONGs que no le gustaban porque antes habían trabajado en Guatemala. Hasta en los talleres de derechos o de cualquier tema se iban a meter, por eso las mujeres nos pusimos de acuerdo y cuando ellos entraban empezábamos a hablar de temas que les daban vergüenza como de la menstruación, los órganos del cuerpo, la homosexualidad... entonces rápido se iban y nos dejaban trabajar... Lo peor era cuando encontraban en los campamentos a compañeros que no tenían su FM y ningún papel. Muchas veces se los llevaron y ya no los volvimos a ver, dicen que los golpeaban y después los aventaban al otro lado...Siempre teníamos que andarnos cuidando de ellos y de los de Migración que casi eran lo mismo..."

La participación de las mujeres organizadas fue fundamental para su desarrollo y el de sus familias durante el refugio y la preparación de su retorno. El rompimiento que se dio con el refugio de las tradicionales estructuras comunitarias y de parentesco abrió espacios para cambios culturales en su participación y organización. Un ejemplo importante de organización de las mujeres es Mamá Maquín (MMQ) que empezó a funcionar en 1990 a pesar de la oposición de COMAr. Su objetivo, siempre pensando en el retorno fue la preparación y la participación de las mujeres para lograr cambios en su situación y posición social —un 
gran reto para quienes han sido sometidas por siglos a un modelo cultural androcentrista - En poco tiempo lograron la alfabetización de muchas integrantes de la organización y la capacitación en Derechos Humanos, con una clara posición contra las desigualdades de género, etnia y clase. MMQ empezó a trabajar en 1990 y para 1993 tenía trabajo en 85 campamentos de Chiapas con más de 7 mil mujeres. (Olivera, 1999).

"Lo que más me gustó del refugio fue que aprendimos muchas cosas, muchas aprendieron a leer y a hablar la castilla, tuvimos talleres de salud, de derechos de las mujeres, aprendimos a hacer programas de radio y así nos comunicábamos con los campamentos, ...sobre todo aprendimos a vivir organizadas como mujeres, había 3 organizaciones Mamá Maquín que era la más grande, antes de que empezaran los retornos en el 92 éramos como 12 mil en Chiapas, Campeche y Quintana Roo. ACNUR nos reconoció y nos apoyó, otra organización era Tierra Viva, otra no me acuerdo su nombre porque cambió, pero como que correspondíamos a las organizaciones de Guate y teníamos trabajo en los 3 estados...Nuestro objetivo era el retorno, que las mujeres fueran tomadas en cuenta por las Comisiones Permanentes de Refugiados para la negociación con el gobierno, para escoger los lugares en donde compraron las tierras para los bloques de retorno... nos costó que nos aceptaran porque eran hombres, pero lo logramos... No todas participábamos igual, las kekchís eran las que se apartaban más, ellas querían vivir como vivíamos en Guatemala, casi no salían de sus campamentos, muchas no aprendieron la castilla... así igual como llegaron así se fueron... Había otras que no querían retornar, ellas tampoco participaban mucho aunque si algo, eran las que lograron comprar tierras o que vivían en terrenos que compró la diócesis, como las de la Gloria y las de San Lorenzo ellas se quedaron, pero también otras que aunque no tenían tierra, tuvieron miedo de volver..."
Las refugiadas también confrontaron muchos problemas, los niños casi no eran aceptados en las escuelas mexicanas, los jóvenes empezaron a trabajar; muchos, como los de Campeche y Quintana Roo se fueron a Cancún a trabajar en la construcción y los servicios,

“...las madres no estaban muy de acuerdo en que se fueran porque trajeron otras mañas, otras costumbres... lo que más nos preocupó es que se empezaron a dar violaciones de las jovencitas, algunas eran antes de que se juntaran las parejas, porque aquí la costumbre cambió, eso de las pedidas ya casi no se hacía, entonces se las llevaban... otra mala costumbre que se dio en varios campamentos, es que los hombres tenían dos mujeres como se hacía antes sobre todo entre las kankobales, pero aquí las mujeres ya no aceptaban...También hubo papás que hicieron su mujer a sus hijas, sobre todo los que eran viudos. La licenciada de ACNUR intervino. Aquí en el campamento de Corralito le quitaron a un papá sus dos hijas que además de tener hijos con ellas las tenía como prisioneras, no dejaba que asomaran fuera de la casa y las golpeaba mucho, estaba como loco por tanto trago..."

\section{Las que se quedaron a vivir en México}

Los Acuerdos firmados el 8 de Octubre de 1992 entre CEAR en representación del gobierno de Guatemala y las Comisiones Permanentes —que incluían la representación de las mujeres organizadas- y que después se integraron a los Acuerdos de Paz, dieron paso a partir de 1993 hasta 1998 a un paulatino de retorno colectivo y organizado de la mayor parte de los refugiados "con las garantías a la vida, la integridad personal; la libre asociación, organización y movimiento; así como de tierra para vivir y la entrega inmediata de documentación personal" (IM-GRICAR, 1999: 79).

Pero más de catorce mil refugiados decidieron quedarse en México acogiéndose al derecho de inserción 
que marca el Estatuto de Refugiados. El conflicto de elegir entre regresar a su tierra y permanecer en un lugar que no era suyo, pero aparentemente más seguro, se desenvolvió en diferentes niveles: la familia y la comunidad. Al nivel doméstico, en la mayor parte de los casos la decisión de retornar se tomó conjuntamente, pero hubo casos en los que las mujeres no tuvieron voz, ni voto; con todo, hubo mujeres que no siguieron a los maridos que habían decidido regresar y otras más que de común acuerdo se quedaron con los hijos. A nivel de la comunidad, los que decidieron quedarse recibieron críticas,

“...nos dijeron que traicionábamos a nuestro país, que preferíamos estar sometidos a los mexicanos que ser libres en Guatemala, pero veíamos que los que ya habían regresado estaban sufriendo porque en los lugares de retorno no había nada..."

La mayor parte de las que se quedaron forman familias con sus esposos o compañeros y sus hijos, que generalmente nacieron en el refugio y tienen legítimamente todos los derechos como mexicanos. Algunas se quedaron porque, sobre todo los jóvenes que llegaron pequeños o nacieron después, se negaron a irse, hacerlo les suponía un problema de identidad, de temor y carencia de recursos en Guatemala. Exceptuando a los que viven en tierras que compraron o les dio la iglesia como los de San Lorenzo, los "asimilados" viven muy dispersos, formando grupos cuando más de 10 ó 15 familias y ya sin ayuda de ACNUR, siguen estando bajo el control de la COMAR que, a decir de las mujeres, los ha presionado para se vayan a Campeche, amenazándolos con quitarles su FM2. Su situación económica es muy difícil, pues siguen sin tierra y el trabajo cada vez es más escaso que antes, sólo consiguen de temporales cuando es tiempo de cosecha en Chamic o en Tapachula. Algunas familias se han reunido para comprar tierras:
"Cinco años luchamos por la tierra. Somos 24 socios, hay algunas mujeres socias, para comprar la tierra de 8 hectáreas a un señor que antes la rentaba; pero a veces no tenemos dinero para comer, sólo para pagar la letra".

En 1998 los que se quedaron, hombres y mujeres, se organizaron en la Coordinadora de Integración de Desplazados a Chiapas (CIDECH), "con el objetivo de conseguir documentación de residentes permanentes, lugares apropiados para vivir, tener acceso a los servicios públicos de los mexicanos y gestionar proyectos con la cooperación internacional"' (CIDECH, 1999), pero la COMAR siempre obstaculizó su trabajo:

“.. y nos decían que no tenemos derecho a organizarnos porque seguimos siendo extranjeros, que lo que el país pudiera darnos lo haría a través de ellos... tampoco nos ha permitido organizarnos como mujeres..."

Algunos dirigentes de CIDECH, trataron de contar con el apoyo del PRI, lo que causó descontento y muchos dejaron la organización, la COMAR, desde que salió ACNUR los presionó para que la dejaran, ahora prácticamente no existe. "El exilio mantiene a esta población como damnificada de la represión y la guerra en sus país de origen y como víctimas de la indiferencia y ambigüedad gubernamental, así como de la xenofobia y negligencia de la sociedad civil mexicana” (González, 1990).

La discriminación y la violación de los derechos de esta población son constantes, un claro ejemplo es el caso de una mexicana por nacimiento a quien la representación del IFE le niega el registro para obtener su credencial de elector, con el argumento de que es hija de refugiados guatemaltecos, aun cuando cuenta con acta de nacimiento. La falta de reconocimiento legal les impide participar en proyectos de gobierno y adquirir tierras, pues aun si tuvieran dinero, no tienen carta de naturalización. Ser propietarias es imposible para aquellas 
mujeres que al separarse de sus maridos o compañeros quedaron indocumentadas, porque los reconocidos legalmente para el retorno eran ellos, con lo que viven en la ilegalidad.

Por añadidura, la Comisión Mexicana de Ayuda a Refugiados (COMAR) otorgó préstamos con intereses a los hombres, jefes de familia guatemaltecos, dinero que ellos no pudieron devolver. Muchos retornaron sin pagar, ahora la COMAR condiciona la entrega de cartas de naturalización al pago de la deuda. El no tener definido su status jurídico de naturalización las hace muy inseguras y vulnerables política y económicamente. La tensión permanente provoca que las refugiadas adopten una postura ambivalente: viven con miedo y odio a las instituciones gubernamentales, que las han amenazado con regresarlas a Guatemala si se organizan o hacen cualquier lucha, pero por otro lado, necesitan la asistencia del gobierno, dada la precariedad de su situación.

La cotidianidad de las mujeres es de carencias vitales: La mayor parte de sus hogares no cuentan con los servicios públicos básicos, no tienen agua potable, drenaje, letrinas suficientes, ni energía eléctrica. Sienten que el trato que les dan en las clínicas, en las escuelas y en las poblaciones cercanas a donde viven es discriminatorio por ser refugiadas e indignante por ser pobres. Incluso la preparación de sus alimentos les es difícil. Debido a la falta de combustible cocinan con leña que es escasa, y para conseguir el agua que utilizan para beber deben caminar largas distancias para acarrearla de los ríos.

Las cartas de naturalización les facilitarían la lucha por su bienestar, pero violando los artículos $6^{\circ}$ y $15^{\circ}$ de la Declaración Universal de los Derechos Humanos y el Art. 30 de la Constitución Mexicana, la COMAR ha retenido sus documentos y, a decir delas participantes en los talleres (Na'Snopel 2003, 81-87), ha condicionado su entrega al saldo de la deuda añeja. Los intereses crecieron y para ellos son impagables y, aunque la deuda fue contraída por los hombres jefes de familia, la represalia se extiende a las mujeres y al resto de la familia, no obstante que la documentación es de carácter personal. En 2001, el CIDECH envió cartas a Xóchitl Gálvez, directora de la Oficina para la Atención a los Pueblos Indios, para que interviniera en el caso, pero no recibieron respuesta.

En estas condiciones de miseria e inseguridad no puede pensarse siquiera que las mujeres puedan desarrollarse con plenitud. Su posición subordinada también es grave, pues les impide concederse el derecho de tomar decisiones y aprovechar sus capacidades, lo que además perpetúa los sistemas de marginación. Siguen reproduciendo los modelos de subordinación, al no compartir responsabilidades con su pareja y asumiendo una posición de servilismo ante los otros.

Sin duda les falta dinero para sobrevivir. Resuelven su manutención diaria con empleos temporales como peones en cafetales y ranchos, trabajo que comparten hombres y mujeres, aunque éstas últimas se ocupen además de las labores del hogar — arduas y en lugares que no cuentan con servicios públicos_-, su salario es de sólo 15 pesos en promedio, la mitad de lo que pagan a los hombres por un día de trabajo. Tampoco hay modo de capacitarse para el trabajo y, como consecuencia, los hombres emigran a Cancún, el Distrito Federal y a Estados Unidos, lo cual significa abandono y sobrecarga de trabajo para las mujeres.

Pero las "asimiladas" no sólo tienen problemas jurídicos, económicos y de salud, sino que viven también agobiadas por el trauma psicológico ocasionado primero por la persecución, luego por el rechazo y la discriminación, por los duelos no resueltos, la dificultad de superar en el refugio muchas pérdidas, las separaciones dolorosas, la inestabilidad y la desintegración familiar, problemas que llevan marcados en sus cuerpos y en sus identidades sin que los hayan podido superar. El desplazamiento que han vivido las refugiadas guatemaltecas además de darse en una situación de control opresivo, generó en ellas dos tipos de respuestas, por un lado tienen una actitud de víctimas de la injusticia, por el otro lado se han visto obligadas a buscar alternativas 
de subsistencia y a exigir sus derechos ante el gobierno mexicano; pero siempre en una posición de subordinación ante el poder mexicano, a riesgo de perder la posibilidad de residir en el país.

\section{III Consideraciones finales}

A manera de conclusión podemos apuntar que la interculturalidad como concepto que se refiere a los intercambios culturales entre grupos social y culturalmente diferentes, siempre debe contextualizarse como parte de la situación económica y política a nivel personal, local, regional y nacional y de las consecuentes relaciones desiguales (género, clase, etnia, edad...) en que viven los agentes que intervienen en el proceso. Esto nos permitirá entender la dinámica de la cultura más allá de lo aparente y descubrir las contradicciones de los poderes que están en juego obedeciendo a intereses económicos y políticos en diferentes niveles de contradicción y confrontación; es decir, que si queremos explicarnos la naturaleza y dinámica de las causas y consecuencias de los intercambios culturales, debemos entender la interculturalidad como parte y consecuencia de las relaciones desiguales de poder en el contexto del sistema capitalista neoliberal en que vivimos y no como un simple proceso de intercambio de productos, costumbres o ideas. En los ejemplos mencionados, en donde apenas nos asomamos a esta compleja dinámica, queda claro que los desplazamientos y los intercambios culturales y sociales que los han provocado y los que se suceden en los nuevos ámbitos de asentamiento han modificado, a veces muy violentamente, las formas aparentes de vida de las mujeres indígenas que llamamos situación de género, clase y etnia, pero que no hacen desaparecer las desigualdades en las posiciones sociales, que llamamos condición de género, etnia y clase, sino las resignifica de acuerdo con la nueva realidad en que viven y con las nuevas formas de articulación económica y política que establecen con el sistema social imperante. Asimismo, se advierte que hacia el interior de los grupos, los cambios culturales, sobre todo los causados o inducidos desde el poder, producen diferenciaciones, reacomodos y conflictos internos muy diversos y cambiantes con efectos en las relaciones sociales y económicas, en los modelos y formas culturales, así como en los referentes identitarios y los sistemas de valoración. Los cambios interculturales generan por momentos dinámicas disgregadoras, pero cuando los grupos en contacto, definen sus espacios, se reacomodan y alcanzan cierta estabilidad en las relaciones, hacen surgir nuevas formas de identidad y nuevos sistemas culturales como los que hemos llamado de "ciudadanía étnica urbana" en el caso de los y las desplazadas tzotziles en San Cristóbal y de sumisión al control opresivo del poder oficial en el caso de los y las refugiadas "asimiladas" que las ubica como guatemaltecas en un plano inferior, subordinado y discriminatorio de lo mexicano y los mexicanos en todos los aspectos de su existencia. La interculturalidad produce asimismo cambios en el entorno social y económico de los lugares y grupos en donde se asientan, produciendo nuevas formas de relación, de poder y de identidad cultural en la población. En el caso de San Cristóbal, la indianización de la ciudad impuesta con los desplazamientos ha transformado las representaciones simbólicas de lo indio y lo coleto, ha cambiado la imagen urbana, a afectado el racismo excluyente de los coletos y los ha obligado a aceptarlos como miembros diferentes de su ciudad. En las identidades los cambios interculturales son significativos. A pesar de la gran diversidad de historias y de reacciones personales, se advierte que la mayoría de las desplazadas tzotziles en San Cristóbal han transformado su cultura sin perder su identidad étnica al adaptarse a la nueva situación. A diferencia de las guatemaltecas en donde el peso de la discriminación que significa ser refugiadas guatemaltecas, ha propiciado, en forma de defensa, adoptar la cultura campesina de los lugares en donde viven para ser aceptadas por los 
mexicanos. La mayor parte de ellas ya no hablan su idioma, ni visten sus trajes, ni quieren ser identificadas como guatemaltecas. Otro aspecto significativo en las identidades es que la inseguridad personal en que viven no sólo propicia su subordinación, sino las ha inmovilizado en relación con la exigencia y definición en el ejercicio de sus derechos; mientras tanto, las mujeres desplazadas de San Cristóbal en una actitud de fuerte movilización ciudadana han conquistado espacios de participación, han acrecentado sus poderes y mantienen una posición de lucha para resolver o superar las desigualdades que padecen: pobreza, amenazas de violación, carencia de servicios, exclusión de la propiedad, etcétera. Desde el punto de vista de las estructuras globales de poder económico y político, las diferencias son menores entre ambos grupos. Su inserción ha implicado formas de relación económica y política para resolver su sobrevivencia que además de ser diferentes a las de sus comunidades de origen, las colocan en una posición de mayor subordinación y dependencia de la dinámica del mercado, del poder del Estado y de las políticas neoliberales, que son muy parecidas en ambos casos: el trabajo informal, inseguro y mal pagado; la venta de artesanías sin el justo reconocimiento y valoración de su trabajo, la dependencia de las estructuras de poder y corrupción controladas. Esta subordinación, compartida por todos los miembros de su familia y la población que las ha acogido, es parte de la dinámica intercultural excluyente y discriminatoria de género, clase y etnia, en donde el poder lo tienen los países ricos y las empresas transnacionales.

\section{Notas}

${ }^{1}$ La investigación, con financiamiento del Instituto de las Mujeres y la Oficina de la Presidencia para la Atención a las Mujeres Indígenas contó con la valiosa colaboración de la doctora Adriana Luna Castellanos, Perla Yeminá Jiménez y Carmelita Méndez, estudiantes de Antropología de la FCS de la Universidad Autónoma de Chiapas. Talleres, entrevistas y observaciones en las comunidades complementaron las experiencias directas de desplazamiento acompañadas y vividas por la autora.

${ }^{2}$ La investigación incluyó a los desplazados a causa del conflicto entre el EZLN y el gobierno, pero no se incluyen por falta de espacio. Las técnicas utilizadas fueron entrevistas a profundidad y encuentros colectivos en los cuales a través de talleres las mujeres analizaron su situación y condición de desplazadas.

${ }^{3}$ Llamamos condición de género a la posición de mayor o menor poder que tienen y se reconoce a las mujeres en las instituciones y en la sociedad en general. Situación de género se refiere a las formas específicas, diferentes y aparentes de la realidad que viven las mujeres en cada caso, que son producto de prescripciones normativas y por lo tanto más fáciles de cambiar que la condición de género.

${ }^{4}$ Tomamos estos conceptos de Bourdieu (1997) para designar los mandatos o prescripciones sociales, que conformadas históricamente y transmitidas generacionalmente, tienen un doble carácter: son trascendentes en tanto que, introyectadas inconscientemente definen las posiciones de poder de las personas en la sociedad de acuerdo con su sexo y los capitales económicos y culturales que poseen. Son normativas en tanto definen la forma concreta de vivir esas posiciones sociales, es decir las formas aprobadas de ser, pensar y actuar diferentes entre hombres y mujeres, en cada sociedad. A diferencia de las trascendentes, las prescripciones normativas cambian de forma y significado con mayor facilidad y dan posibilidades a las personas de aceptarlas, rechazarlas o cambiarlas.

${ }^{5}$ Según Naciones Unidas, se entiende por desplazados internos: "las personas o grupos de personas que se han visto forzadas u obligadas a escapar o huir de su hogar o de lugar de residencia habitual, en particular como resultado o para evitar los efectos de un conflicto armado, en situaciones de violencia generalizada, de violación a los derechos humanos o de catástrofes naturales o provocadas por el ser humano y que no han cruzado una frontera estatal o internacional reconocida". (CDHFBC, 2001, p. 5).

${ }^{6}$ La cantidad de desplazados en Chiapas es significativamente menor a los desplazados por las guerras en Perú o Colombia durante las dos últimas décadas. En Colombia de enero de 2000 a julio de 2001 fueron desplazadas 251757 personas (Red de Solidaridad Social de Colombia, 2001).

${ }^{7}$ Aún sin garantías, durante los dos primeros años del gobierno de Salazar 271 familias fueron transferidas a comunidades de 
10 municipios, de ellas sólo retornaron a sus lugares de origen 140. (La Jornada, 25 de agosto 2002)

${ }^{8}$ Los coletos llaman colonias "exclusivas" a las que habitan sólo indígenas desplazados.

${ }^{9}$ En 1976 después de impedir las actividades impulsadas por el cura, como la introducción de la energía eléctrica, que ponía en peligro el negocio de venta de velas y petróleo, las autoridades expulsaron al cura y ejercieron una mayor corporativización y control sobre los feligreses. Esto decidió el abandono - con negociaciones intermitentes - de la parroquia de Chamula de parte de la Diócesis de San Cristóbal.

${ }^{10} \mathrm{La}$ expansión del protestantismo se dio cuando el antiguo y prestigioso ilol, Miguel Cashlán dejó de curar porque "aprendió otra religión con los gringos, que era muy buena... evitaba las enfermedades y ya no se necesitaba gastar en velas, aguardiente, pollos..” (López A. 2002). Al difundirse esta militancia se dio la primera expulsión. Miguel Cashlán representó la fuerza política de los expulsados en el exilio, hasta 1980, año en que fue asesinado por pistoleros de los caciques de Chamula.

${ }^{11}$ Uno de los conflictos más grandes se dio en Chalchihuitán, cuando paramilitares pagados por los caciques asesinaron a varias decenas de personas que se opusieron a la expulsión de maestros críticos y catequistas en 1983. Con las movilizaciones que siguieron se logró que el gobierno detuviera temporalmente a los implicados pero dejó escapar al presidente municipal, principal responsable de la masacre. ${ }^{12}$ La dotación ejidal en Chamula data de 1961, beneficiando a 111 campesinos con 4446 Has, que se entregaron hasta 1981 afectando las propiedades de Banabil, Las Rosas, La Quinta, El Carmen, Dolores y otras. Algunas de ellas contaban con certificados de inafectabilidad.

${ }^{13}$ Partido Revolucionario Mexicano, antecesor del PRI, Partido de la Revolución Mexicana que duró en el poder hasta el 2000.

${ }^{14}$ Uno de los más conocidos es Domingo López Ángel, líder originalmente adventista promotor de la CRIACH, fundador histórico y defensor de la Hormiga que finalmente es reconocida en 1992. Después de cambiar de religión y ocupar diversos cargos públicos a la sombra del PRI y del PRD, fue acusado de múltiples delitos y encarcelado de 1998 a 2000. Ahora es dirigente musulmán en la Hormiga.

${ }^{15}$ En las colonias de desplazados están presentes prácticamente todos los partidos del estado pero los que tienen más afiliados son el PRI, PRD, PAN y el Frente Cardenista.
${ }^{16}$ Las organizaciones de comerciantes indígenas están afiliadas a la CROM, la CNC, la CTM, la USLO, la CRIACH, la ORIACH y la OPEACH. (Hvostoff, 2001).

${ }^{17}$ Más de 20 mil desplazados por la religión en San Cristóbal viven con otros desplazados económicos y por la guerra, en más de 20 colonias, entre ellas Nueva Esperanza, Getzemaní, Mazariegos, La Hormiga, San Antonio de los Montes, Palestina, La Quinta, La Isla, Tlaxcala, Explanada del Carmen, La Florecilla, Santa Cruz, Cascajal y Primero de Mayo.

${ }^{18}$ La información entrecomillada a partir de este párrafo se ha obtenido en las entrevistas y talleres que se realizaron como parte de la investigación. Nos comprometimos con las mujeres desplazadas a no publicar sus nombres ni elementos que pudieran comprometerlas. Los textos están grabados y pueden consultarse a través de la autora de este artículo.

${ }^{19}$ Los índices de analfabetismo se han reducido; la mayoría de los niños tienen acceso a la educación primaria, auque la deserción de las niñas es más alta que la de los varones. Muchos jóvenes indígenas de estas colonias se inscriben en la secundaria, pero son pocos los que terminan y cursan la preparatoria. Hombres y mujeres, pero sobre todo ellas, tienen dificultades fuertes con materias como español inglés y matemáticas. No obstante algunas llegan a la Universidad y terminan una carrera de las que se imparten en San Cristóbal. Personalmente, siendo profesora en la Facultad de Ciencias Sociales, me encontré con serias dificultades para sacar a los alumnos (as) indígenas adelante. Desde mi punto de vista, no es falta de capacidad su problema, sino un manejo muy elemental del castellano que les dificulta entender los conceptos y hacer abstracciones, colocándolos en una situación de desventaja con los no indígenas que por cierto, en general, también presentan deficiencias profundas en su preparación.

${ }^{20}$ A diferencia de otras mujeres indígenas, las mujeres Chamulas que viven en sus comunidades, heredan tierra, tienen borregos, participan en la producción campesina y en el pequeño mercado de frutas, verduras y artesanías. Su posición en la familia les permite tener una autoridad reconocida, sin dejar de estar subordinadas por su condición materna, por las dobles jornadas de trabajo que cumplen y por la exclusión del sistema de cargos político religiosos de sus comunidades.

${ }^{21} \mathrm{El}$ saldo de tres dramáticas décadas de exterminio fue de un millón de desplazados, más de 100 mil muertos, 90 mil desaparecidos, más de 50 mil viudas, 250 mil huérfanos y 440 aldeas arrasadas (Ardón, 1998: 104). 
${ }^{22}$ En 1983 y 1984 las incursiones del Ejército de Guatemala al territorio mexicano fueron incontables, entre las más significativas se mencionan las masacres en los campamentos de Chajul, Chupadero y Puerto Rico.

${ }^{23}$ El salario mínimo para el campo en Chiapas era de $\$ 18.50$ en esa época.

\section{Bibliografía}

Aguirre Beltrán, Gonzalo, 1967, Regiones de Refugio, Instituto Indigenista Interamericano, México.

Aparici, Elvira, 1994, “Ethos”, en Sendón y otras, Feminismo Holístico De la realidad a lo Real, Cuadernos de Agora Bilbao, Vizcaya, pp. 119-133.

Aramoni, Dolores y Gaspar Morquecho,1997, “La otra mejilla...pero armada. El recurso de las armas en manos de los expulsados de San Juan Chamula", Anuario 1996, CESMECA, México, pp. 553- 611.

Ardón, Patricia, 1998, La Pazy los Conflictos en Centroamérica, Consejo para el Desarrollo de Centroamérica-OXFAM Great Bretain, Guatemala.

Bastos, Santiago y Camus Manuela, 2001, "La Interculturalidad ¿una respuesta para la Guatemala del siglo xxı?”, Ponencia presentada en el Cuarto Congreso de Estudios Mayas, FLACSO, Ms. Guatemala.

Bonfil, Guillermo, 1999, Pensar Nuestra Cultura, Alianza Editorial, México.

Bourdieu, Pierre, 1997. Razones Prácticas. Sobre la teoria de la acción, Ed. Anagrama, Barcelona.

CIDECH, 1999, "Nuestro Proceso de Asimilación en México, Coordinadora de Integración de Desplazados en Chiapas", Tríptico, Comitán.

Mujeres/Mujeres Para El Diálogo. México.

Cunningham, Mirna y Ligia Siézar, 2001, “Género, Racismo e Interculturalidad. La experiencia en la Universidad de las Regiones Autónomas de la Costa Caribe Nicaragüense", Revista Universitaria, URACCAN, Nicaragua, pp 6-48.

Escalante, María de la Paloma, 1995, "Cambio y políticas modernizadoras en Chiapas”, en Diana Guillén (coordinadora), Chiapas, una modernidad inconclusa, Instituto Mora, México. Foulcault, Michel, 1992, Genealogía del Racismo, de la guerra de razas al racismo de Estado, Ed. La Piqueta, Madrid.

García Canclini, Néstor, 1989, Culturas Híbridas Estrategias para Entrar y Salir de la Modernidad, Ed. Grijalbo, México.
González, Rafael, 1990, Refugiados Centroamericanos no reconocidos en México, Tesis de Licenciatura, Centro de Estudios Latinoamericanos, UNAM, México.

Henríquez, Elio, 2002, "Entrevista al relator de la ONU para desplazados Internos", La Jornada, 25 y 28 de agosto, México.

Hernández Navarro, Luis, 1994, “Corrupción. Tierras compradas a precio de oro”, La Jornada, 10 de junio, México. Hernández Castillo, Aída, 2001, "Entre el etnocentrismo feminista y el esencialismo étnico. Las mujeres indígenas y sus demandas de género", Debate Feminista, Racismo y Mestizaje, núm. 24, Octubre, México, pp. 206-229.

Herrera, Joaquín, 2002, "Derechos Humanos, Interculturalidad y Racionalidad de Resistencia", Revista Derechos Humanos y Desarrollo. núm. XII, noviembre-diciembre, Universidad Pablo de Olavide, Sevilla.

Hopenhayn, Martín, 1995, Ni Apocalípticos, ni Integrados, FCE, México.

IM-Gricar, 1999, "El proceso de Retorno de Refugiados Guatemaltecos. Una visión desde la Mesa de Negociación”, Guatemala.

Hvostoff, Sophie, 2001, "Indios y Coletos: por una relectura de las relaciones interétnicas en San Cristóbal de las Casas. Chiapas", Centro Francés de Estudios Mexicanos y Centroamericanos, Ms.

Isunza, Ma. Enriqueta, 1997, Implementación de la política de desarrollo urbano-regional. El caso de la ciudad de San Cristóbal de Las Casas, 1980-1995, Tesis de Maestría en Estudios Regionales, UNACH, Chiapas.

Juliano, Dolores, 1999, La causa saharabui y las mujeres, Ed. Icaria, Barcelona.

Lagarde, Marcela, 1988, "La triple opresión de las mujeres Indígenas”, México Indígena, núm. 21, México, pp. 11-15.

—, 1997, Los Cautiverios de las Mujeres. Madresposas, monjas, presas, putas y locas, unAm, México.

Lamas, Martha, 1996, "Usos, dificultades y posibilidades de la categoría de Género”, En: Marttha Lamas (coord), Elgénero: la construcción social de la diferencia sexual, unAM, Grupo Editorial Porrúa, México, pp. 327-365.

Mcleod, Morna y Luisa Pérez-Armiñan, (compiladoras), 2000, Identidad: Rostros sin máscara (Reflexiones sobre Cosmovisión, Género y Etnicidad), Ed. Maya Nojib’sa, Guatemala.

Morquecho, Gaspar, 1992, Los indios en un Proceso de Organización: La ORIACH. Tesis de licenciatura en Antropología, 
Facultad de Ciencias Sociales, UNACH, San Cristóbal de Las Casas, Chiapas.

—, 1998, "Las políticas indigenistas en la formación de los cacicazgos en los Altos de Chiapas", Quehacer Cientifico en Chiapas, Revista de Divulgación Científica de la UNACH, Volumen 1, núm. 1, Tuxtla Gutiérrez, Chiapas, pp. 18-23.

—, 2002, San Cristóbal: buele a indio. Ediciones Pirata, San Cristóbal de Las Casas, Chiapas.

Na' Snopel, 2003, Mujeres desplazadas en Chiapas. Informe. Oficina de la Presidencia Regional de Atención a la Población Indígena/Instituto Nacional de las Mujeres, México.

Olivera, Mercedes, (Coord.), 1994, De refugiadas a retornadas.

Memorial de las experiencias de las mujeres refugiadas en Chiapas, CIREFCA, Comitán.

-, (Coord,), 1999, Nuestra experiencia ante los retos del futuro, ACNUR-Mamá Maquín, México.

—, y Vázquez Gabriela, (en prensa), “Genero y Neolberalismo en Chiapas", en Olivera, Mercedes (Coord), De subordinaciones y rebeldias: Mujeres indigenas de Chiapas, UNACH-CONACYT, UNICACH. Osorio, Jaime, 2001, Fundamentos del análisis social, UAM-FCE, México.

Palencia, Tania, 1999, Género y Cosmovisión Maya, proyecto de desarrollo Santiago, Editorial Saquil Tzij, Guatemala, C.A.

CIACH, CONPAZ, SIPRO, 1997, Para entender Chiapas. Chiapas en cifras, México.

Pérez Enríquez, Ma. Isabel, 1994, Expulsiones indigenas. Religión y migración en tres municipios de los Altos de Chiapas: Chenalhó, Larráinzary Chamula, Claves Latinoamericanas, México.

Pisano, Margarita, 2000, El triunfo de la masculinidad, Colección Mujeres, Ediciones Pirata, San Cristóbal de Las Casas, Chiapas.

—, 2001, "Feminismos del Siglo XXI", La Triple Jornada, núm. 37, Suplemento de La Jornada, 4 de septiembre, México.
Red de Solidaridad Social, 2001, Sistema de estimación del desplazamiento forzado por fuentes contrastantes, en www.cajpe.org.pe CAJPE.

Reyes, Ma. Eugenia, 1998, "Los acuerdos agrarios en Chiapas", en Reyes, Moguel y Van der Haar, Espacios Disputados: Transformaciones Rurales en Chiapas, UAM-X y Colegio de la Frontera Sur, México, pp. 21-48.

Rus, Jan, 1995a, “¿Guerra de castas según quién?”, En Viqueira y Ruz (editores), Chiapas: Los rumbos de otra historia. UNAM, CIESAS, Universidad de Guadalajara. pp.145-174. México.

—, 1995b, "La Comunidad Revolucionaria Institucional. La subversión del gobierno indígena en los altos de Chiapas. 1936-1968", en Viqueira y Mario Ruz (editores), Chiapas: Los rumbos de otra historia, UNAM, CIESAS, Universidad de Guadalajara, México, pp. 251-277

SIPAZ Informe, Mayo 2000, Vol. V, núm. 3, Chiapas.

Sendón, Victoria, María Sánchez, Montserrat Gutín y Elvira Aparici, 1994, Feminismo bolístico, de la realidad a lo real, Ed. Cuadernos del Agora, Bilbao, Vizcaya.

Schmelkes, Silvia, 2001, "Los retos de la educación intercultural en México”, CINTESTAV. Ponencia al encuentro interculturalidad, Ms México.

Valenzuela Feijó, José, (1992), “El estilo neoliberal y el caso mexicano", en Asa Cristina Laurell (coordinadora), Estado y politicas sociales en el neoliberalismo, Fundación Ebert, México.

Vázquez, Gabriela, 2001, El Modelo Neoliberal en México: Pobreza, Polarización y Reducción del Espacio de la Politica Social en México, Tesis para obtener el Título de Licenciada en Sociología, FCPS, UNAM.

Villafuerte, Daniel y García María del Carmen (1994), “Los altos de Chiapas en el contexto del neoliberalismo: causas y razones del conflicto indígena", en Silvia Soriano (coordinadora) A propósito de la insurgencia en Chiapas, ADICH, México. 